\title{
29
}

\section{Communicating Integrated Analysis Research Findings}

\author{
Mashrekur Rahman and Md. Munsur Rahman
}

\subsection{Introduction}

A key component of any research is to ensure that results and implications are communicated to those most affected and those in a position to successfully implement any response as well as those who have committed time and effort to the research; in this case it is the relationship between ecosystem services and poverty at a community and socialecological system level to the local communities who provided survey information (Chap. 23) and decision-makers. This helps the configuration and adoption of adaptive responses to a changing environment, which, with the historical and projected changes discussed earlier in this book, necessitates the modes of survival and livelihoods found within the delta to adapt and evolve. Understanding the context, having situational awareness and executing plans through partnership form an indispensable part of effective research dissemination at a community level. It is therefore

\footnotetext{
M. Rahman $(\bowtie) \bullet$ Md. Munsur Rahman Institute of Water and Flood Management, Bangladesh University of Engineering and Technology, Dhaka, Bangladesh 
important to provide information and perspectives of practical value to communities and associated Non-Governmental Organisations (NGOs) as well as local government.

There are diverse ways in which research can be disseminated at a community and local governance level. To reach and be understood by the remotest of rural population in Bangladesh, knowledge is best translated into a non-scientific, jargon-free and practical package. This may consist of a variety of tailored dissemination tools, such as indigenous cultural performances or press releases. There are pros and cons to each of these tools in reaching audiences, and therefore a combination of these tools constitutes a stronger dissemination package and increases the chances of meaningful impact.

\subsection{Engaging News Media}

Bangladesh in recent years has seen an impressive rise in the number of local and national newspapers, news channels, online news portals and radio stations. The number of internet users in Bangladesh surpassed 60 million in 2016 according to Bangladesh Telecommunication Regulatory Commission ${ }^{1}$, allowing news media to deliver news of relevant interest to millions of rural people, directly to their homes. Translating knowledge from research findings to newsworthy segments requires certain strategies and ethical considerations before dissemination. Indeed, contextual awareness forms a major part of the strategy for research dissemination in Bangladesh; cultural differences, understanding what the public are willing to accept and political interests are some of the aspects to be aware of while engaging with the media. Critically, language should be easy to understand for the general population. For example, in case of newspaper articles and blogs, it is imperative to publish in both native Bengali and English languages to encourage uptake. Bengali newspapers have overwhelmingly larger reader numbers when compared to English language newspapers particularly in rural Bangladesh. Social media can be an effective tool to further proliferate impact.

A significant portion of the rural population in Bangladesh is either illiterate or has limited literary skills. Printed media cannot therefore 
ensure inclusiveness. Television and radio, as audio-visual media, have the capacity to improve this although there are still millions of people in the coastal region without access to electricity. For television and radio appearances, it is vital to plan ahead on the questions and answers to ensure the findings are not misrepresented or misinterpreted. Planning ahead also averts the possibility of revealing unconfirmed findings, which may cause confusion or ill-founded responses. Overtly political statements should be avoided or, where strictly necessary, made indirectly to avoid conflict. Proper acknowledgement of contributors is also a substantial part of research ethics (Sula 2016).

Research described in this book has been published in various national newspapers and blogs. A brief presentation on the significance of ecosystem services and the project was delivered at the First Climate Leaders Convention 2015 in Dhaka, the Fourth Asia Youth Summit in Japan and various other national and international forums. An interview with Prof. Dr. Md. Munsur Rahman was published by the Bengali news daily Kaler Kantho in August 2016. In the interview, a variety of questions were answered ranging from the goals and vision of research to the development of Bangladesh Delta Plan 2100. In the same month, an article titled 'Children of the Bengal Delta' was published in the Daily Observer Bangladesh, followed by three consecutive articles in the month of September 2016: 'Bangladesh's rich ecosystem and its role in poverty alleviation', 'Exploring the changes in ecosystem resources' and 'Ecosystem science, policy and people'. These articles were aimed at raising awareness on ecosystem protection in the wake of climate change and summarised the research in a manner understandable by the reader. After publication, these materials were shared in various social media platforms to increase their reach and to generate feedback from readers. Feedback was mostly positive; the general consensus from those who responded on ecosystem protection was overwhelmingly supportive of the work. Readers also emphasised the value of the larger and more comprehensive circulated news pieces in national Bangladesh papers to build support for protecting ecosystems against inappropriate development and industrialisation.

There are obvious challenges while engaging the national media. One of the major challenges is persuading the newspapers of the significance of this information, with some papers preferring to prioritise political stories over environmental issues. Building a relationship with media 
entities in Bangladesh is often time consuming. A dedicated media communication programme is therefore beneficial to expedite dissemination of research in the country.

\subsection{Dissemination to Stakeholders}

Disseminating research findings at a local and regional level is aimed at ensuring inclusiveness, and a regional to local strategy should be adopted. This approach advocates that the most practical and enduring method for passing information back to communities is to engage with the regional network of NGO's who in turn have sustained links into the local population. Within the study area, a series of stakeholder workshops (Fig. 29.1) with the most remote of the local coastal population of Bangladesh were found to be particularly beneficial. The specific objectives of these workshops were (i) to get feedback and input from regional stakeholders on research findings and appropriate dissemination techniques, (ii) to review the current status of local issues through communication with local participants and (iii) to introduce indigenous 'Pot Song' as a research dissemination

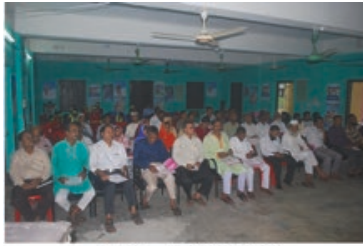

Nalchity $(02 / 08 / 2016)$

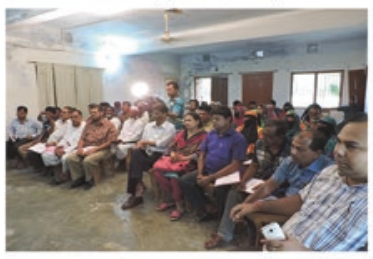

Sharankhola (05/08/2016)

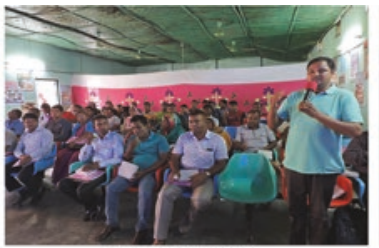

Tala (04/08/2016)

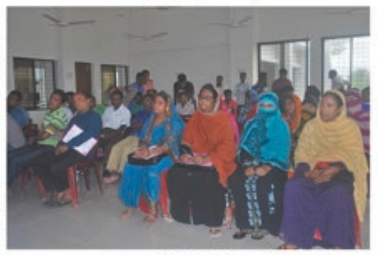

Koyra (06/08/2016)

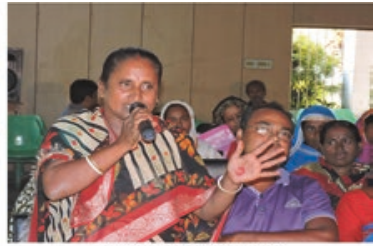

Dumuria (04/08/2016)

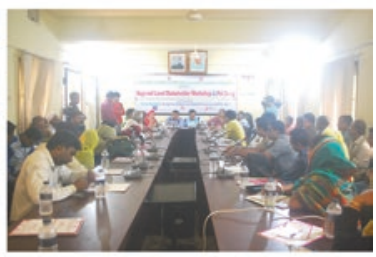

Bhandaria (07/08/2016)

Fig. 29.1 Regional level stakeholder workshops. The total number of people involved in the process was 360, representing local and regional institutions (Photographs: Mashrekur Rahman) 
tool for rural populations. These workshops were held in six locations across the coastal belt of Bangladesh: (i) Nalchity, Jhalokathi; (ii) Tala, Satkhira; (iii) Dumuria, Khulna; (iv) Sharankhola, Bagerhat; (v) Koyra, Khulna; and (vi) Bhandaria, Pirojpur. Among these locations, Sharankhola and Koyra are in close proximity to the Sundarbans, and often serve as entry-points into the mangrove forest. Tala and Dumuria are located inside the Western Estuarine System of Bangladesh and are subject to a wide range of environmental issues. Nalchity and Bhandaria face their own unique set of challenges.

\subsubsection{Pot Songs: Talking with Communities in Their Own Language}

Pot songs (Bengali: পটসঙ্গীত) are south-west Bangladesh's indigenous cultural performances which entertain hundreds of thousands of people at a community level. These songs are traditionally performed by local entertainment groups at village congregations and events where they depict certain social situations through rolling paintings, improvised lyrics and traditional dancing. Low-income people in remote coastal regions, who rarely have access to print or electronic media, draw much pleasure from these performances, while the songs can subtly convey vital social messages. Although pot songs have previously been used to raise awareness on social responsibility and raising disaster awareness, they are rarely used to disseminate specific research findings.

Pot songs were performed at the six regional level workshops (Fig. 29.2). The song used paintings depicting ecosystem degradation scenarios and the ways in which rural population can partake in improving them. The bespoke song written for these workshops attempted to cover all the research findings (Nicholls et al. 2015, 2016) in a very non-technical language and using local examples. It begins with a warm welcome to the listeners and continues by describing visible and perceptible changes in the weather and environment, gradually linking to global climate change, potential impacts on ecosystems and ultimately consequences for lives and livelihoods. The song also makes the listeners aware of the consequences of sea-level rise, land subsidence, salinity intrusion, the inter-relationship between ecosystems and human 


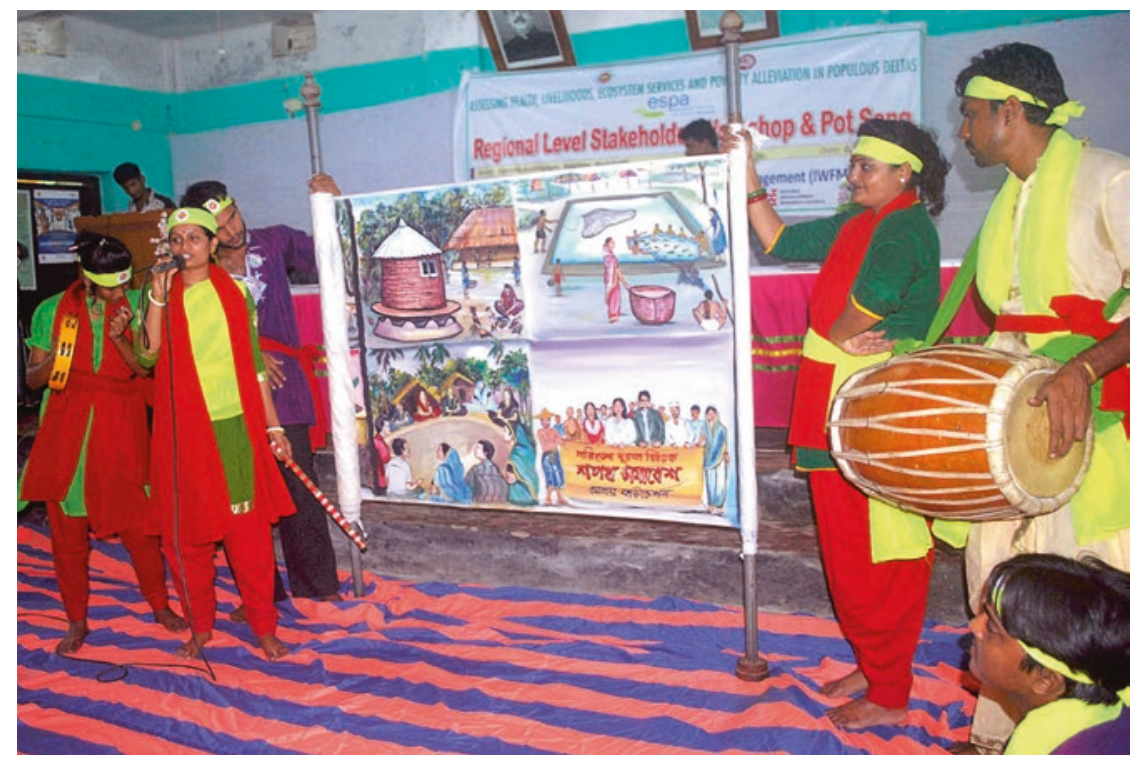

Fig. 29.2 Pot Song based on ecosystem research being performed at Nalchity, Jhalokathi (Photograph: Mashrekur Rahman)

well-being (Hossain et al. 2017) and why a healthy ecosystem has important benefits. Agricultural malpractices such as use of chemical fertilisers and pesticides, overexploitation of land resources, deforestation and deliberately allowing saline water into land for shrimp aquaculture are discouraged in the song. The song lyrics then include warnings on depleting groundwater, dwindling river flow and predicted salinity intrusion, reiterating the importance of reducing water pollution and conserving freshwater. As the song nears its ending, the protective role of the Sundarbans is highlighted: that people living in the study area are shielded from cyclones and storm surges by the mangroves (Sakib et al. 2016) and therefore afforestation is encouraged. At the end of the song, unity among people, cooperation with the government and non-government bodies, and taking a stance against corruption are emphasised. The last line translates into 'survival is not possible without saving the environment'.

This effort was widely appreciated by participants taking part in the workshop, including the participants from remote places who came there to make their voices heard. "Not everybody can understand scientific 
terms; particularly the underprivileged population, who have not been exposed to quality education amenities", said one participant who came from an area damaged by Cyclone Sidr. "This song is an extremely entertaining way to know about our ecosystem services and how they are quintessential to our survival and what we can do to protect it", he added.

Attendees in general wanted to see this song played in rural centres, bazaars, schools and other places of congregation for wider circulation of knowledge through entertainment. Audiences suggested that these messages may also be delivered using staged dramas, storytelling and other local forms of entertainment. Therefore, it may be recommended that these types of performances are staged regularly at the most remote coastal regions. Documentaries on such performances may be broadcast by television channels to augment their popularity. More tailored dissemination tools and other versions of the song may be introduced to further bolster the research dissemination process.

\subsubsection{Stakeholder Workshops Outcomes}

Among the guests and participants at the stakeholder workshops were Upazila Chairman, vice-chairman, government officers, local administrative staffs, teachers, community leaders, people's representatives, professionals, farmers, fishermen, journalists and people from various other walks of life. The mix of participants was equally diverse for all of the workshops. ${ }^{2}$ Following the programme, presentations and the Pot Song performance, an interactive open discussion session was held with the participants, the key points from which are summarised in Table 29.1 and Fig. 29.3.

\subsubsection{Stakeholder Feedback}

These stakeholder workshops and pot songs enabled participants to engage in meaningful discussions about the issues regarding ecosystem degradation and its impact on their lives and livelihoods. Dissemination of scientific research, through indigenous entertainment performances such as this pot song, allows the most laid-back of remote population to understand the perils facing them. It may even empower these people with the 


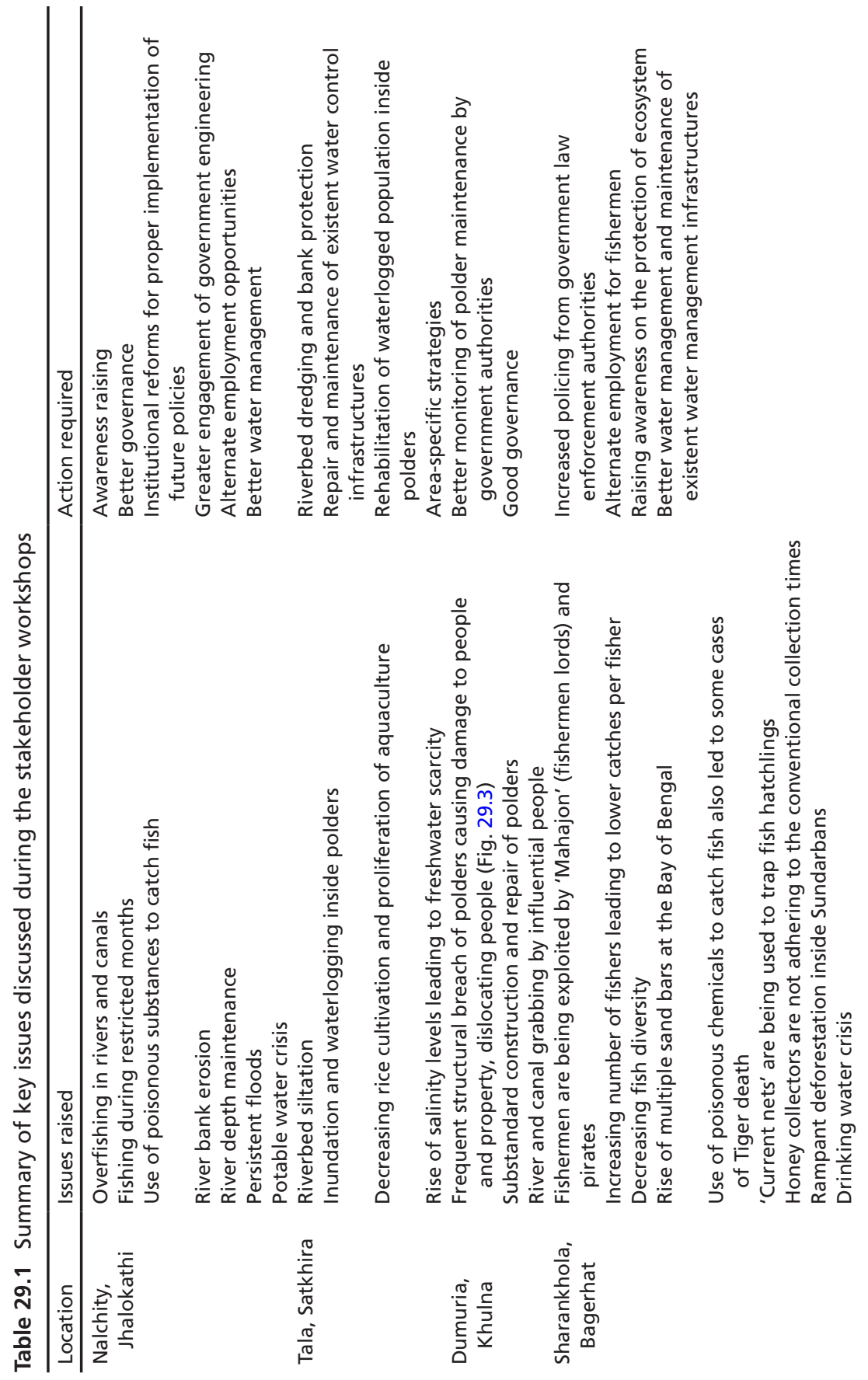



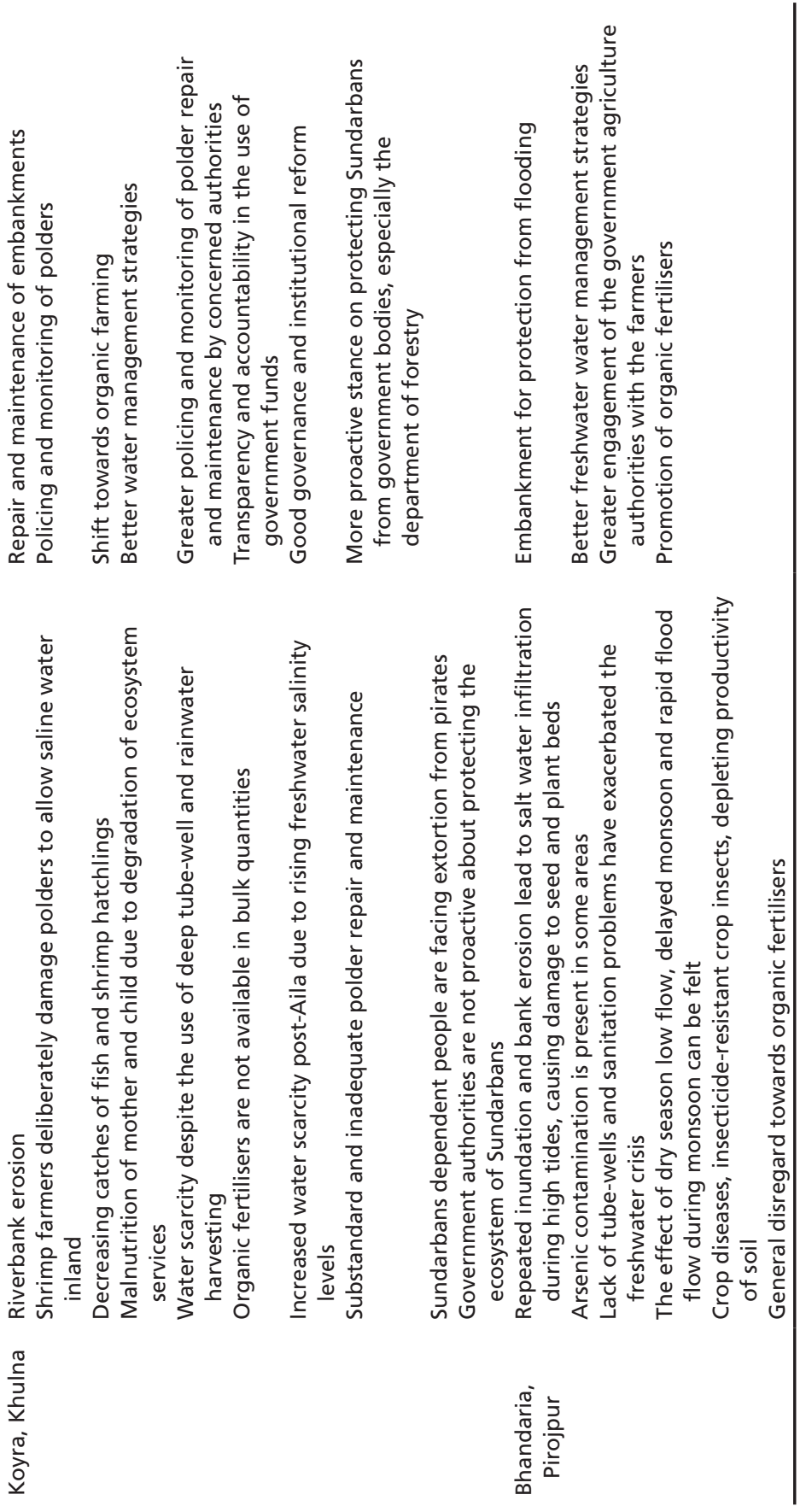


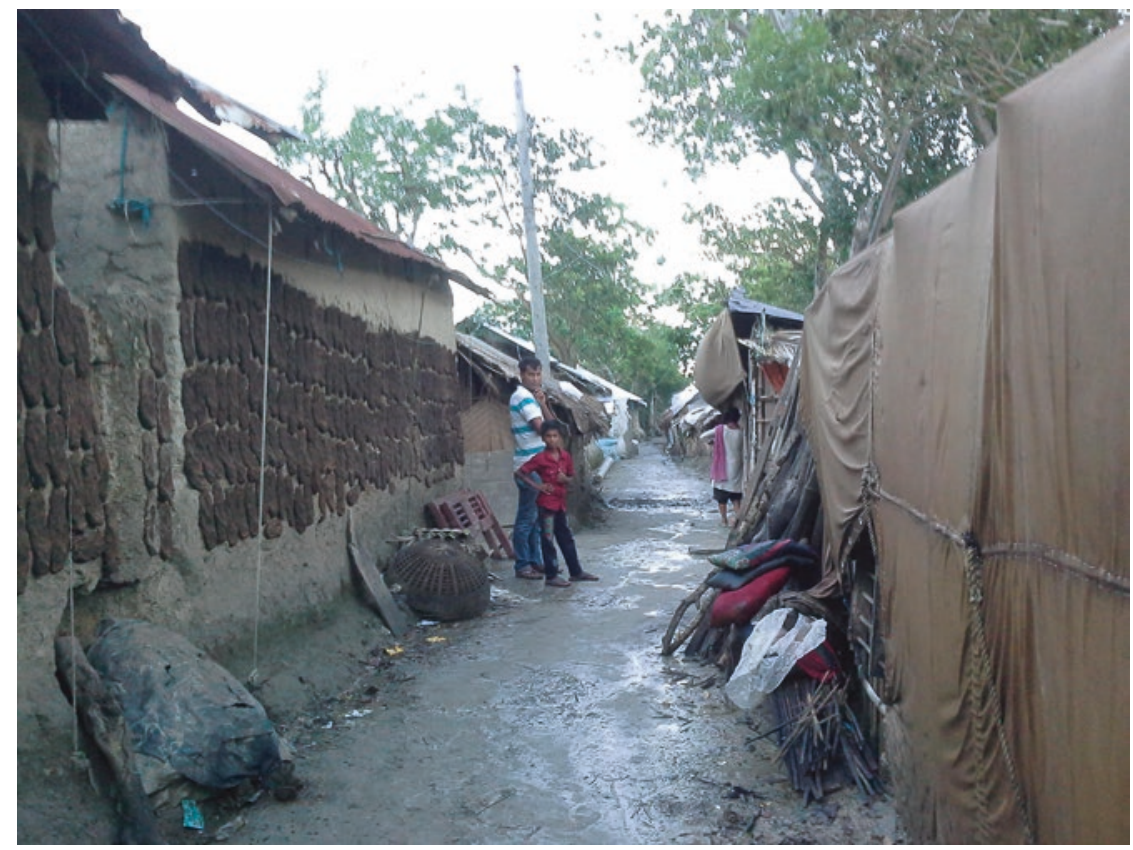

Fig. 29.3 Locals living in shanties on polder 29 after it was breached by the Bhadra River (Photograph: Mashrekur Rahman)

knowledge to cope with future scenarios. Pot songs in the six stakeholder workshops discussed in this chapter were appreciated by the audiences, particularly for the innovative path it took to reach them at a very basic level. Such performances, if used more widely for proliferating research findings, have the potential to generate significant impact among the vulnerable coastal population of Bangladesh, an opinion seconded by many audiences. It is however important to realise that different communities respond to diverse tailored dissemination tools. NGOs and government institutions attending these workshops were intrigued by the level of penetration these performances were able to achieve. They expressed their willingness to use such research dissemination techniques in their future endeavours to reach communities. It is important to ensure expert consultation while developing these dissemination tools, and also take into account political and religious sensitivity, especially 
considering the conservative nature of audiences in remote regions. Audience feedbacks should be recorded for future reference and may be used to improve on the performances. Local languages and cultures differ quite noticeably from place to place, opening opportunities of area-specific dissemination tools to further bolster their reach. Government and NGOs can collaborate in the future to use such Pot Song performances to better disseminate research findings, as well as deliver important social messages which may eventually result in elevated socio-economic stature and reduced vulnerabilities of the coastal population.

\subsection{Conclusions}

Plenty of scientific research conducted in Bangladesh ends up on bookshelves and in scientific archives, inaccessible for the mass populationdepriving people from knowledge and benefits. Disseminating research findings effectively to people who need it most is probably as important as conducting the research itself. The true value of science is only realised when it benefits humankind and protects the planet's precious natural resource systems. Fresh new ideas and innovative approaches to such dissemination such as the pot songs can be the way forward.

\section{Notes}

1. www.btrc.gov.bd

2. For participants, see Participating organisation list at front of this book.

\section{References}

Hossain, M.S., F. Eigenbrod, F. Amoako Johnson, and J.A. Dearing. 2017. Unravelling the interrelationships between ecosystem services and human wellbeing in the Bangladesh delta. International Journal of Sustainable Development \& World Ecology 24 (2): 120-134. https://doi.org/10.1080/135 04509.2016.1182087. 
Nicholls, R.J., P. Whitehead, J. Wolf, M. Rahman, and M. Salehin. 2015. The Ganges-Brahmaputra-Meghna delta system: Biophysical models to support analysis of ecosystem services and poverty alleviation. Environmental ScienceProcesses and Impacts 17 (6): 1016-1017. https://doi.org/10.1039/c5em90022k. Nicholls, R.J., C.W. Hutton, A.N. Lázár, A. Allan, W.N. Adger, H. Adams, J. Wolf, M. Rahman, and M. Salehin. 2016. Integrated assessment of social and environmental sustainability dynamics in the Ganges-BrahmaputraMeghna delta, Bangladesh. Estuarine, Coastal and Shelf Science 183, Part B: 370-381. https://doi.org/10.1016/j.ecss.2016.08.017.

Sakib, M., F. Nihal, A. Haque, M. Rahman, R. Akter, M. Maruf, M. Akter, S. Noor, and R.A. Rimi. 2016. Afforestation as a buffer against storm surge flooding along the Bangladesh coast. 12th International Conference on Hydroscience Engineering Hydro-Science; Engineering for Environmental Resilience, November 6-10, Tainan.

Sula, C.A. 2016. Research ethics in an age of big data. Bulletin of the Association for Information Science and Technology 42 (2): 17-21. https://doi.org/10.1002/ bul2.2016.1720420207.

Open Access This chapter is licensed under the terms of the Creative Commons Attribution 4.0 International License (http://creativecommons.org/licenses/ by/4.0/), which permits use, sharing, adaptation, distribution and reproduction in any medium or format, as long as you give appropriate credit to the original author(s) and the source, provide a link to the Creative Commons license and indicate if changes were made.

The images or other third party material in this chapter are included in the chapter's Creative Commons license, unless indicated otherwise in a credit line to the material. If material is not included in the chapter's Creative Commons license and your intended use is not permitted by statutory regulation or exceeds the permitted use, you will need to obtain permission directly from the copyright holder.

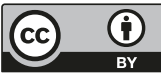

